\title{
Predictors of Nonadherence to NCCN Guideline Recommendations for the Management of Stage I Anal Canal Cancer
}

\author{
Adam J. Kole, MD, PhDa; John M. Stahl, MDª; Henry S. Park, MD, MPHª; Sajid A. Khan, MD; \\ and Kimberly L. Johung, MD, PhD
}

\begin{abstract}
Background: Definitive chemoradiotherapy (CRT) is recommended by the NCCN Clinical Practice Guidelines in Oncology (NCCN Guidelines) for Anal Carcinoma for all patients with stage I anal canal cancer. Because these patients were not well represented in clinical trials establishing CRT as standard therapy, it is unclear whether NCCN recommendations are being closely followed for stage I disease. This study identified factors that predict for NCCN Guideline-concordant versus NCCN Guideline-discordant care. Methods: Using the National Cancer Data Base, we identified patients diagnosed with anal canal carcinoma from 2004 to 2012 who received concurrent CRT (radiotherapy [RT] 45.0-59.4 Gy with multiagent chemotherapy), RT alone (45.0-59.4 Gy), or surgical procedure alone (local tumor destruction, tumor excision, or abdominoperineal resection). Demographic and clinicopathologic factors were analyzed using the chi-square test and logistic regression modeling. Results: A total of 1,082 patients with histologically confirmed stage I anal cancer were identified, among whom 665 (61.5\%) received CRT, $52(4.8 \%)$ received RT alone, and $365(33.7 \%)$ received only a surgical procedure. Primary analyses were restricted to patients receiving CRT or excision alone, as these were most common. Multivariable analysis identified factors independently associated with reduced odds of CRT receipt: low versus intermediate/high tumor grade (adjusted odds ratio [AOR], 0.21; 95\% Cl, 0.14-0.29; $P<.001$ ), tumor size $<1 \mathrm{~cm}$ vs 1 to $2 \mathrm{~cm}$ (AOR, $0.24 ; 95 \% \mathrm{Cl}, 0.17-0.35 ; P<.001)$, age $\geq 70$ versus 50 to 69 years $(\mathrm{AOR}, 0.36 ; 95 \% \mathrm{Cl}, 0.24-0.54 ; P<.001)$, male sex (AOR, $0.63 ; 95 \% \mathrm{Cl}, 0.45-0.90 ; P=.009)$, and treatment at an academic versus a non-academic facility $(\mathrm{AOR}, 0.58 ; 95 \% \mathrm{Cl}, 0.41-0.81$; $P=.002$ ). Conclusions: Despite the NCCN recommendation of CRT for stage I anal cancer, at least one-third of patients appear to be receiving guideline-discordant management. Excision alone is more common for patients who are elderly, are male, have small or low-grade tumors, or were evaluated at academic facilities.
\end{abstract}

J Natl Compr Canc Netw 2017;15(3):355-362

\section{Background}

Anal cancer constitutes 2\% to 3\% of gastrointestinal malignancies, with approximately 8,000 new cases estimated for 2016 in the United States. ${ }^{1}$ Currently, concurrent chemoradiotherapy (CRT) with 5-fluorouracil (5-FU) and mitomycin-C (MMC) is considered standard-of-care therapy for all patients with nonmetastatic anal canal cancer. ${ }^{2,3}$ Whether such an aggressive treat-

From aDepartment of Therapeutic Radiology, and 'Department of Surgery, Surgical Oncology Section, Yale School of Medicine, New Haven, Connecticut.

Submitted September 13, 2016; accepted for publication November 30 , 2016.

Dr. Park has disclosed that he has received an honorarium and travel expenses as a speaker for Varian Medical Systems. The remaining authors have disclosed that they have no financial interests, arrangements, ment is necessary for stage I (T1NO) disease has been less clear, however, because these patients were either excluded or underrepresented in the most influential anal cancer clinical trials. ${ }^{4-9}$

Radiotherapy (RT) or excision alone have been explored as less aggressive alternatives for early-stage anal canal cancers, although these studies have been primarily single-arm and retrospective. ${ }^{10-14}$ Other studies have

affiliations, or commercial interests with the manufacturers of any products discussed in this article or their competitors.

Author contributions: Study conception: Kole, Stahl, Park, Johung. Acquisition of data: Stahl. Primary data analysis: Kole. Data analysis, drafting of manuscript, and critical revision: Kole, Stahl, Park, Khan, Johung.

Correspondence: Kimberly L. Johung, MD, PhD, Smilow Cancer Hospital, 35 Park Street, Lower Level, New Haven, CT 06511.

E-mail: kimberly.johung@yale.edu 
examined CRT with reduced doses of RT to minimize treatment toxicity. ${ }^{15,16}$ Without strong prospective evidence available to support the efficacy and safety of RT or excision alone, NCCN has recommended definitive CRT for all patients with locoregional anal canal cancer since the inception of the second version of the NCCN Clinical Practice Guidelines in Oncology (NCCN Guidelines) for Anal Carcinoma in 2002.,17 Whether NCCN Guidelines are being followed specifically for patients with stage I anal canal cancer is unclear.

This study used the National Cancer Data Base (NCDB) to examine whether practice patterns for stage I anal canal cancer have been consistent with standard practice guidelines recommending CRT, as published by NCCN over the past decade. We then identify factors that predict the use of NCCN Guideline-concordant versus NCCN Guidelinediscordant therapy.

\section{Methods}

\section{Study Population}

The NCDB is a joint project by the Commission on Cancer $(\mathrm{CoC})$ of the American College of Surgeons (ACS) and the American Cancer Society. Established in 1989, the NCDB is a comprehensive, nationwide, facility-based oncology data set, capturing approximately $70 \%$ of all newly diagnosed malignancies in the United States. The data used in this study are derived from a deidentified NCDB file. The ACS and the CoC have not verified and are not responsible for the analytic or statistical methodology used or the conclusions drawn from these data by the investigators.

We identified patients in the NCDB diagnosed from 2004 to 2012 with histologically confirmed clinical T1NO anal canal cancer with the following histologies: squamous cell carcinoma, basaloid squamous cell carcinoma, or basaloid carcinoma (ICD-0-3 histology codes 8070-8078, 8083, 8123); anal margin cancers are not included within the anal cancer participant use file. Patients with unknown surgical status or those who underwent surgery $>90$ days after diagnosis were excluded. For the purposes of this study, surgical procedures were defined as "local tumor destruction alone" (photodynamic therapy, electrocautery, fulguration, cryosurgery, laser, or thermal ablation), "excision alone" (polypectomy or excisional biopsy), or "APR" (abdominoperineal resection). Because specific chemotherapeutic agents are not specified within the NCDB, we limited our study to patients receiving multiagent chemotherapy, because this would be consistent with 5-FU/MMC use. Patients receiving RT were required to receive doses between 45.0 and 59.4 Gy and start RT within 90 days of diagnosis. Concurrent CRT was defined as initiation of multiagent chemotherapy and RT within 14 days of each other. Because the NCDB includes all methods of treatment received by patients as part of the first course of therapy, some patients were coded as undergoing a surgical procedure with subsequent definitive RT or CRT (eg, excisional biopsy followed by RT to 54 Gy within 90 days of diagnosis). These patients were included in either the RT or CRT subgroup, respectively. Patients were required to have known tumor grade and size for study inclusion. In order to minimize immortal time bias, which would affect treatment groups that did not complete a full course of RT, we excluded all patients who died within 3 months of diagnosis. ${ }^{18}$

Patients within our study cohort are shown in Figure 1. Notably, in order to prevent patient identifiability, the NCDB does not allow reporting of groups of $<10$ patients. For the initial analysis, only patients undergoing treatment with excision alone or CRT were examined. A sensitivity analysis was subsequently performed which reintroduced patients undergoing treatment with local tumor destruction, APR, or RT alone. "NCCN Guideline-concordant" patients were defined as those receiving CRT, whereas "NCCN Guideline-discordant" patients were defined as those undergoing local tumor destruction, excision alone, APR, or RT alone.

\section{Statistical Methods}

Patient demographic and clinical factors were compared using the chi-square test to identify predictors of receipt of therapy (excision alone or CRT). Patient demographic factors included age, sex, race, Charlson-Deyo comorbidity score, diagnosis year, insurance coverage, estimated income by county of residence, setting of residence, distance to treatment facility, academic or non-academic treatment facility affiliation, and geographic location. Clinicopathologic factors, including tumor size and tumor grade, were also included in chi-square analyses. Human papillomavirus (HPV) status was excluded from chi- 


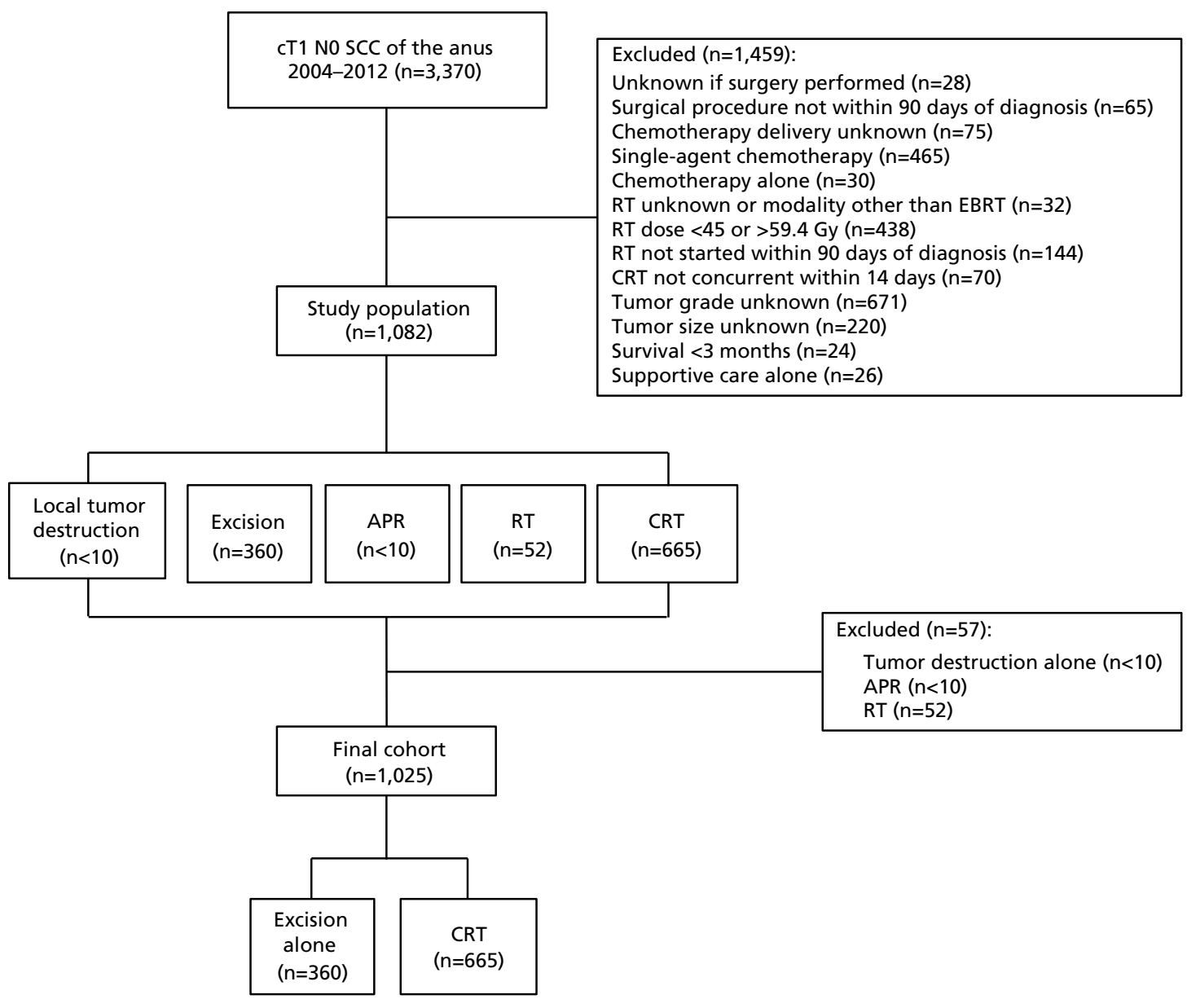

Figure 1. Flow diagram of inclusion criteria and treatment groups.

Note: The National Cancer Data Base does not allow reporting of groups of $<10$ patients.

Abbreviations: APR, abdominoperineal resection; CRT, chemoradiotherapy; EBRT, external-beam radiotherapy; RT, radiotherapy; SCC, squamous cell carcinoma.

square testing due to limited data availability within the NCDB.

Clinicopathologic factors were dichotomized and univariable Cox regression was used to calculate unadjusted odds ratios (ORs) for receipt of CRT versus excision alone. Factors trending towards significance $(P<.10)$ were included in a backward conditional stepwise multivariable logistic regression to identify adjusted ORs (AORs). Factors with $P<.05$ on multivariable regression were considered statistically significant predictors of receipt of CRT versus excision alone. Patients with missing data for variables of interest (detailed in Table 1) were omitted from univariable and multivariable analyses. HPV status was excluded from Cox regression models due to the high proportion of patients with unknown HPV status. We then repeated univariable and multivariable logistic regression as a sensitivity analysis including all patients who received either NCCN Guideline-concordant (CRT) or NCCN Guideline-discordant (local tumor destruction, excision alone, APR, or RT alone) care. Kaplan-Meier analyses were used to compare overall survival (OS) between treatment groups. Unadjusted hazard ratios (HRs) for survival were calculated with univariable Cox regression. Two-sided tests with a $P$ value $<.05$ were considered to be statistically significant. All statistical analyses were performed using STATA/SE 13.1 (StataCorp, College Station, TX). 
Kole et al

\begin{tabular}{|c|c|}
\hline Characteristic & $\begin{array}{c}n(\%) \\
(N=1,025)\end{array}$ \\
\hline \multicolumn{2}{|l|}{ Age, y } \\
\hline Median & 57 \\
\hline$<50$ & $257(25.1)$ \\
\hline $50-69$ & $587(57.3)$ \\
\hline$\geq 70$ & $181(17.7)$ \\
\hline \multicolumn{2}{|l|}{ Sex } \\
\hline Male & $339(33.1)$ \\
\hline Female & $686(66.9)$ \\
\hline \multicolumn{2}{|l|}{ Race/Ethnicity } \\
\hline White & $817(79.7)$ \\
\hline Black & $72(7.0)$ \\
\hline Hispanic & $35(3.4)$ \\
\hline Other/Unknown & $101(9.9)$ \\
\hline \multicolumn{2}{|c|}{ Charlson-Deyo comorbidity score } \\
\hline 0 & $852(83.1)$ \\
\hline$\geq 1$ & $173(16.9)$ \\
\hline \multicolumn{2}{|l|}{ Diagnosis year } \\
\hline 2004 & $60(5.9)$ \\
\hline 2005 & $67(6.5)$ \\
\hline 2006 & $69(6.7)$ \\
\hline 2007 & $86(8.4)$ \\
\hline 2008 & $124(12.1)$ \\
\hline 2009 & $145(14.2)$ \\
\hline 2010 & $150(14.6)$ \\
\hline 2011 & $155(15.1)$ \\
\hline 2012 & $169(16.5)$ \\
\hline \multicolumn{2}{|l|}{ Insurance coverage } \\
\hline None & $33(3.2)$ \\
\hline Private & $587(57.3)$ \\
\hline Medicaid & $60(5.9)$ \\
\hline Medicare & $326(31.8)$ \\
\hline Government/Unknown & $19(1.9)$ \\
\hline \multicolumn{2}{|l|}{ Estimated income } \\
\hline$<\$ 38,000$ & $169(16.5)$ \\
\hline$\$ 38,000$ to $<\$ 48,000$ & $236(23.0)$ \\
\hline$\$ 48,000$ to $<\$ 63,000$ & $273(26.6)$ \\
\hline$\geq \$ 63,000$ & $340(33.2)$ \\
\hline Unknowna & $<10$ \\
\hline \multicolumn{2}{|l|}{ Setting of residence } \\
\hline Metropolitan & $854(83.3)$ \\
\hline Urban & $131(12.8)$ \\
\hline Rural & $19(1.9)$ \\
\hline Unknown & $21(2.1)$ \\
\hline \multicolumn{2}{|c|}{ Distance to treatment facility, miles } \\
\hline$<10$ & $572(55.8)$ \\
\hline $10-19$ & $223(21.8)$ \\
\hline $20-49$ & $155(15.1)$ \\
\hline$\geq 50$ & $75(7.3)$ \\
\hline \multicolumn{2}{|l|}{ Treatment facility type } \\
\hline Non-academic & $626(61.1)$ \\
\hline Academic & $279(27.2)$ \\
\hline Unknown & $120(11.7)$ \\
\hline \multicolumn{2}{|l|}{ Geographic location } \\
\hline Northeast & $189(18.4)$ \\
\hline South & $280(27.3)$ \\
\hline Midwest & $285(27.8)$ \\
\hline West & $227(22.2)$ \\
\hline Unknown & $44(4.3)$ \\
\hline \multicolumn{2}{|l|}{ Tumor size } \\
\hline$<1 \mathrm{~cm}$ & $239(23.3)$ \\
\hline $1-2 \mathrm{~cm}$ & $786(76.7)$ \\
\hline \multicolumn{2}{|l|}{ Tumor grade } \\
\hline Low & $256(25.0)$ \\
\hline Intermediate & $486(47.4)$ \\
\hline High & $283(27.6)$ \\
\hline HPV status & \\
\hline Positive & $56(5.5)$ \\
\hline Negative & $56(5.5)$ \\
\hline Unknown & $913(89.1)$ \\
\hline
\end{tabular}

Abbreviation: HPV, human papillomavirus.

aThe National Cancer Data Base does not allow reporting of groups of $<10$ patients.

\section{Results}

Within the NCDB, we identified 3,370 patients from 2004 to 2012 with histologically confirmed clinical T1N0 anal canal carcinoma. Patients were excluded if surgical status was unknown; the procedure was not performed within 90 days of diagnosis; they did not receive multiagent chemotherapy, as would be consistent with 5-FU/MMC; they received chemotherapy alone; nonstandard doses of RT were delivered; or those undergoing CRT did not receive RT within 14 days of chemotherapy (Figure 1). Given the prognostic significance of tumor grade and size, ${ }^{19-21}$ an additional 671 and 220 patients were excluded, respectively, due to missing data. Our initial cohort included 1,082 patients. Definitive CRT was the most common treatment type received by patients in our study cohort $(61.4 \% ; n=665)$. Excision alone without subsequent additional therapy was observed in a large minority of patients $(33.3 \%$; $n=360$ ), whereas RT without chemotherapy was delivered to only $4.8 \%(n=52)$ of patients. Fewer than 10 patients received either local tumor destruction or APR as the only therapy. Approximately half of the patients within the CRT group $(46.6 \%$; $=310)$ had undergone initial surgery with excision or local tumor destruction before CRT. Because patients who received CRT or excision alone included nearly $95 \%$ of the total cohort, our initial analyses were restricted to these 2 most common treatment groups. Our final cohort included a total of 1,025 patients.

The median age for the entire cohort was 57 years. Most patients were female $(66.9 \%)$, of white race $(79.7 \%)$, had no significant comorbidities $(83.1 \%)$, and were privately insured $(57.3 \%)$. Tumors were primarily 1 to $2 \mathrm{~cm}(76.7 \%)$ and intermediate-to-high grade $(75.0 \%)$. Tables 1 and 2 summarize all measured demographic and clinicopathologic characteristics and the association of these characteristics with treatment type, respectively. We assessed the use of CRT versus excision alone from 2004 to 2012 (Figure 2). Rates of CRT receipt did not change significantly over the study period $(68.4 \%$ in $2004-2007$ vs $63.5 \%$ in $2008-$ 2012; $P=.141)$.

Demographic and clinicopathologic factors were tested using univariable analysis for increased odds of CRT receipt (supplemental eTable 1, available with this article at JNCCN.org). Factors with a trend toward significance (age, sex, race, insurance 
Stage I Anal Cancer Practice Patterns

Table 2. Association of Treatment Type With Patient Demographic and Clinicopathologic Factors

\begin{tabular}{|c|c|c|c|}
\hline \multirow[b]{2}{*}{ Characteristic } & \multicolumn{2}{|c|}{$N(\%)$} & \multirow[b]{2}{*}{$P$ Value } \\
\hline & $\begin{array}{l}\text { Excision } \\
(n=360)\end{array}$ & $\underset{(n=665)}{C R T}$ & \\
\hline \multicolumn{3}{|l|}{ Age, y (ref: 50-69) } & $<.001$ \\
\hline$<50$ & $109(42.4)$ & $148(57.6)$ & \\
\hline $50-69$ & $171(29.1)$ & $416(70.9)$ & \\
\hline$\geq 70$ & $80(44.2)$ & $101(55.8)$ & \\
\hline \multicolumn{3}{|l|}{ Sex (ref: male) } & $<.001$ \\
\hline Male & $162(47.8)$ & $177(52.2)$ & \\
\hline Female & $198(28.9)$ & $488(71.1)$ & \\
\hline \multicolumn{3}{|c|}{ Race/Ethnicity (ref: white) } & .003 \\
\hline White & $274(33.5)$ & $543(66.5)$ & \\
\hline Black & $37(51.4)$ & $35(48.6)$ & \\
\hline Hispanic & $18(51.4)$ & $17(48.6)$ & \\
\hline Other/Unknown & $31(30.7)$ & $70(69.3)$ & \\
\hline \multicolumn{3}{|c|}{ Charlson-Deyo comorbidity score (ref: 0) } & .276 \\
\hline 0 & $293(34.4)$ & $559(65.6)$ & \\
\hline$\geq 1$ & $67(38.7)$ & $106(61.3)$ & \\
\hline \multicolumn{3}{|c|}{ Diagnosis year (ref: 2004-2007) } & .650 \\
\hline 2004 & $17(28.3)$ & $43(71.7)$ & \\
\hline 2005 & $26(38.8)$ & $41(61.2)$ & \\
\hline 2006 & $20(29.0)$ & $49(71.0)$ & \\
\hline 2007 & $26(30.2)$ & $60(69.8)$ & \\
\hline 2008 & $43(34.7)$ & $81(65.3)$ & \\
\hline 2009 & $55(37.9)$ & $90(62.1)$ & \\
\hline 2010 & $60(40.0)$ & $90(60.0)$ & \\
\hline 2011 & $52(33.6)$ & $103(66.5)$ & \\
\hline 2012 & $61(36.1)$ & $108(63.9)$ & \\
\hline \multicolumn{3}{|c|}{ Insurance coverage (ref: private) } & .052 \\
\hline None & $12(36.4)$ & $21(63.6)$ & \\
\hline Private & $185(31.5)$ & $402(68.5)$ & \\
\hline Medicaid & $24(40.0)$ & $36(60.0)$ & \\
\hline Medicare & $129(39.6)$ & $197(60.4)$ & \\
\hline Gov't/Unknowna & 10 & $<10$ & \\
\hline \multicolumn{3}{|c|}{ Estimated income (ref: <63,000) } & .031 \\
\hline$<\$ 38,000$ & $68(40.2)$ & $101(59.8)$ & \\
\hline$\$ 38,000$ to $<\$ 48,000$ & $76(32.2)$ & $160(67.8)$ & \\
\hline$\$ 48,000$ to $<\$ 63,000$ & $79(28.9)$ & $194(71.1)$ & \\
\hline$\geq \$ 63,000$ & $135(39.7)$ & $205(60.3)$ & \\
\hline Unknown ${ }^{a}$ & $<10$ & $<10$ & \\
\hline \multicolumn{3}{|c|}{ Setting of residence (ref: metropolitan) } & .045 \\
\hline Metropolitan & $315(36.9)$ & $539(63.1)$ & \\
\hline Urban & $36(27.5)$ & $95(72.5)$ & \\
\hline Rurala $^{a}$ & $<10$ & 16 & \\
\hline Unknown ${ }^{a}$ & $<10$ & 15 & \\
\hline \multicolumn{3}{|c|}{ Distance to treatment facility, miles (ref: $<10$ ) } & .810 \\
\hline$<10$ & $203(35.5)$ & $369(64.5)$ & \\
\hline $10-19$ & $82(36.8)$ & $141(63.2)$ & \\
\hline $20-49$ & $50(32.3)$ & $105(67.7)$ & \\
\hline$\geq 50$ & $25(33.3)$ & $50(66.7)$ & \\
\hline Treatment facility type & n-academic) & & $<.001$ \\
\hline Non-Academic & $190(30.4)$ & $436(69.7)$ & \\
\hline Academic & $122(43.7)$ & $157(56.3)$ & \\
\hline Unknown & $48(40.0)$ & $72(60.0)$ & \\
\hline Geographic location (re & heast) & & .005 \\
\hline Northeast & $68(36.0)$ & $121(64.0)$ & \\
\hline South & $99(35.4)$ & $181(64.6)$ & \\
\hline Midwest & $79(27.7)$ & $206(72.3)$ & \\
\hline West & $91(40.1)$ & $136(59.9)$ & \\
\hline Unknown & $23(52.3)$ & $21(47.7)$ & \\
\hline Tumor size, cm (ref: <1) & & & $<.001$ \\
\hline$<1$ & $150(62.8)$ & $89(37.2)$ & \\
\hline $1-2$ & $210(26.7)$ & $576(73.3)$ & \\
\hline Tumor grade (ref: low) & & & $<.001$ \\
\hline Low & $165(64.5)$ & $91(35.6)$ & \\
\hline Intermediate & $145(29.8)$ & $341(70.2)$ & \\
\hline High & $50(17.7)$ & $233(82.3)$ & \\
\hline HPV status & & & * \\
\hline Positive & $15(26.8)$ & $41(73.2)$ & \\
\hline Negative & $29(51.8)$ & $27(48.2)$ & \\
\hline Unknown & $316(34.6)$ & $597(65.4)$ & \\
\hline
\end{tabular}

Abbreviations: CRT, chemoradiotherapy; HPV, human papillomavirus. a The National Cancer Data Base does not allow reporting of groups of $<10$ patients.

${ }^{*}$ Chi-squared test not performed due to small sample size.

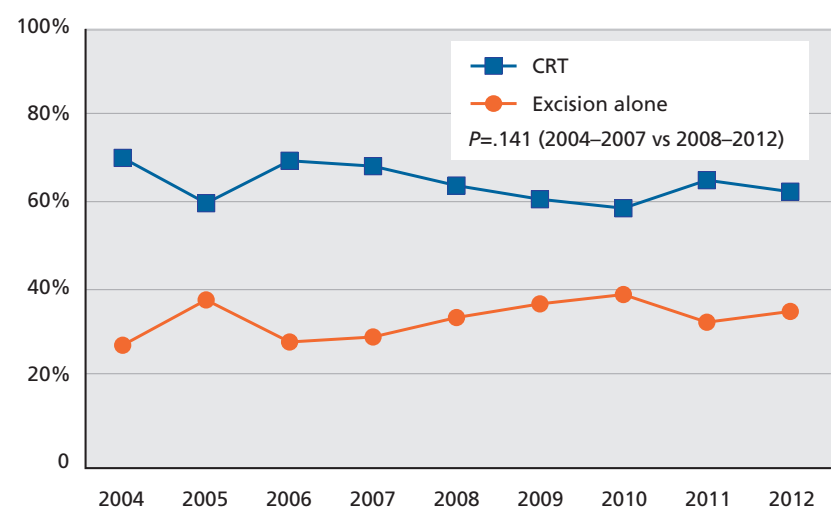

Figure 2. Unadjusted trends in use of CRT versus excision alone during the study period.

Abbreviation: CRT, chemoradiotherapy.

coverage, estimated income, setting of residence, treatment facility type, and tumor size and grade) were included in a multivariable logistic regression model. Multivariable modeling showed that patients who were significantly less likely to receive CRT included those aged $\geq 70$ years versus 50 to 69 years (AOR, 0.36; 95\% CI, 0.24-0.54; $P<.001$ ), male sex (AOR, 0.63; 95\% CI, 0.45-0.90; $P=.009$ ), treatment at an academic versus non-academic facility (AOR, 0.58; 95\% CI, 0.41-0.81; $P=.002)$, tumor size $<1 \mathrm{~cm}$ versus 1 to $2 \mathrm{~cm}$ (AOR, 0.24; 95\% CI, 0.17-0.35; $P<.001)$, and low versus intermediate/high tumor grade (AOR, 0.21; 95\% CI, 0.14-0.29; $P<.001$ ) (Table 3 and Figure 3). OS was not statistically different between patients who underwent excision alone and CRT (5-year OS, $83.8 \%$ vs $87.3 \%$; HR, 0.71; $95 \%$ CI, 0.48-1.04; $P=.079$ ) (Figure 4).

Because patients undergoing local tumor destruction, APR, or RT were excluded from the initial cohort, we performed a sensitivity analysis in which these patients were combined with those receiving excision alone (NCCN Guideline-discordant cohort). We then repeated univariable and multivariable regressions to identify independent factors associated with NCCN Guideline-concordant CRT versus other NCCN Guideline-discordant treatments. Results were similar to those of our initial analysis, with age $\geq 70$ years, male sex, treatment at academic facility, tumor size $<1 \mathrm{~cm}$, and low-grade tumors more likely to be associated with nonstandard NCCN Guideline-discordant therapy (supplemental eTable 2). 


\section{Discussion}

NCCN has recommended concurrent CRT for all patients with locoregional anal canal cancer, including stage I (T1NO) disease, since the second version of the NCCN Guidelines for Anal Carcinoma was published in 2002 (category 2A). ${ }^{17}$ In this study, we used a large national hospital-based database to identify patient and tumor factors that predict for the use of NCCN Guideline-concordant CRT versus other NCCN Guideline-discordant therapies for patients with stage I anal canal cancer. We found that fewer than two-thirds of patients receive NCCN Guideline-concordant CRT as the initial course of therapy. Surgery has fallen out of favor for the primary treatment of anal canal cancer since the early discovery by $\mathrm{Ni}$ gro et $\mathrm{al}^{3}$ that sphincter and tumor removal via APR can be spared when patients receive CRT. However, in our cohort we found that a substantial proportion of patients $(33 \%)$ with stage I anal canal cancer underwent excision alone as definitive therapy. Although NCCN recommends excision alone with adequate margins for patients with well-differentiated T1NO cancers confined to the perianal skin or anal margin, the literature supporting this approach for cancers of the anal

\begin{tabular}{|c|c|c|c|}
\hline \multirow[b]{2}{*}{ Variable } & \multicolumn{3}{|c|}{ Multivariable Analysis } \\
\hline & AOR & $95 \% \mathrm{Cl}$ & $P$ Value \\
\hline \multicolumn{4}{|l|}{ Age, y } \\
\hline$<50$ vs $50-69$ & 0.74 & $0.50-1.09$ & .130 \\
\hline$\geq 70$ vs $50-69$ & 0.36 & $0.24-0.54$ & $<.001$ \\
\hline \multicolumn{4}{|l|}{ Sex } \\
\hline Male vs female & 0.63 & $0.45-0.90$ & .009 \\
\hline \multicolumn{4}{|l|}{ Setting of residence } \\
\hline $\begin{array}{l}\text { Metropolitan vs } \\
\text { non-metropolitan }\end{array}$ & 0.68 & $0.43-1.09$ & .106 \\
\hline \multicolumn{4}{|l|}{ Treatment facility type } \\
\hline Academic vs non-academic & 0.58 & $0.41-0.81$ & .002 \\
\hline \multicolumn{4}{|l|}{ Tumor size, cm } \\
\hline$<1$ vs $1-2$ & 0.24 & $0.17-0.35$ & $<.001$ \\
\hline \multicolumn{4}{|l|}{ Tumor grade } \\
\hline Low vs intermediate/high & 0.21 & $0.14-0.29$ & $<.001$ \\
\hline
\end{tabular}

Abbreviation: AOR, adjusted odds ratio.

canal is limited to small retrospective series from the 1980s. For example, Boman et al ${ }^{10}$ described a small series of patients with superficial anal canal cancers treated at the Mayo Clinic with excision alone, for which local control was achieved
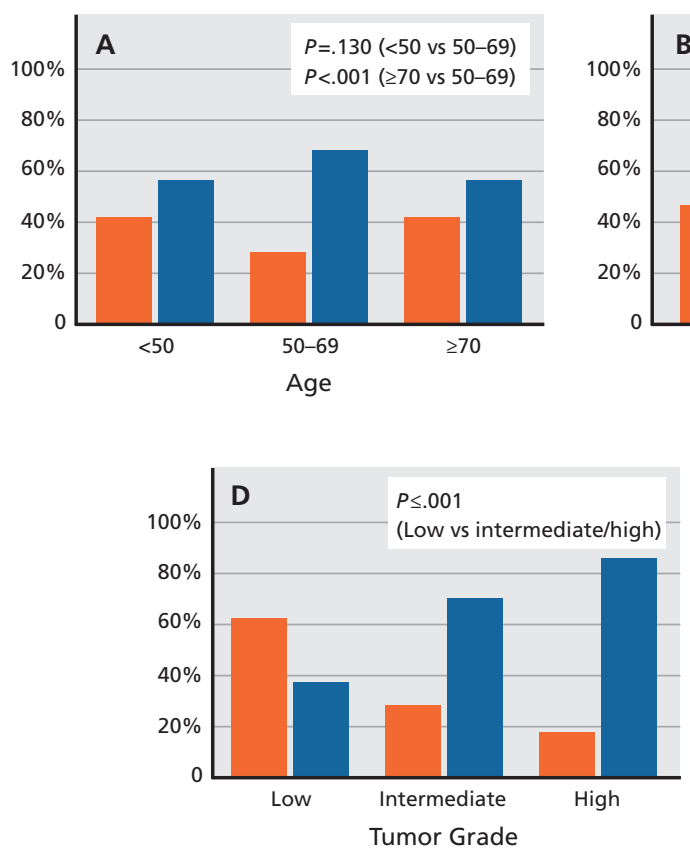
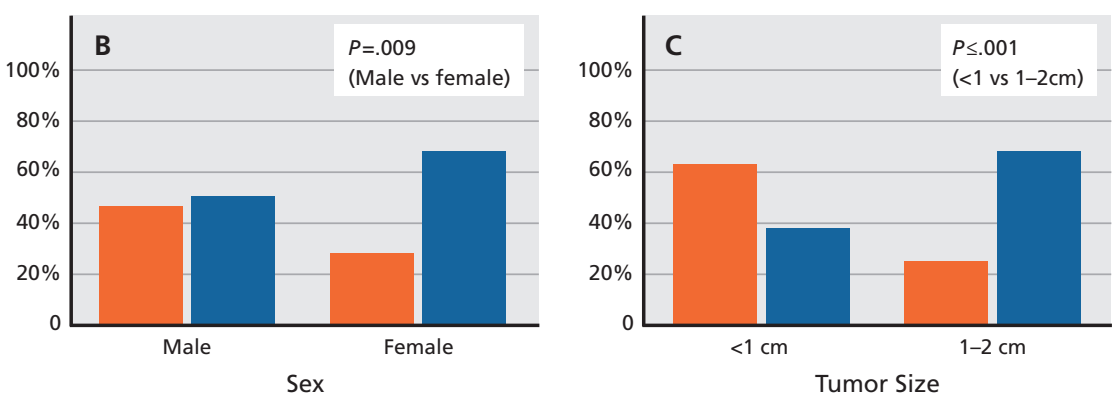

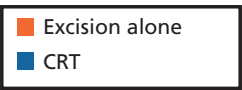

Facility Type

Figure 3. Rates of CRT and excision alone by (A) age, (B) sex, (C) tumor size, (D) tumor grade, and (E) treatment facility type. Abbreviation: CRT, chemoradiotherapy. 


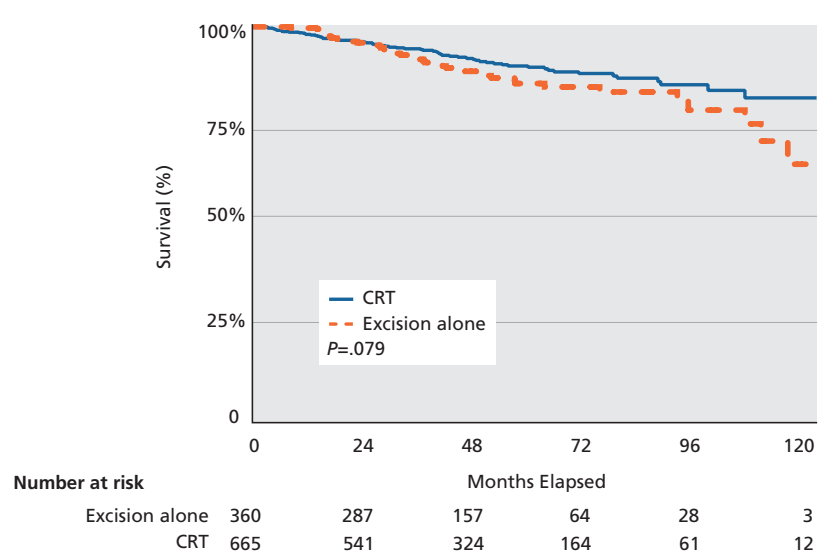

Figure 4. Overall survival for CRT and excision-alone treatment groups. Abbreviation: CRT, chemoradiotherapy.

in $92 \%$ (12 of 13$)$. Others have observed higher rates of local failure, up to $40 \%$, when excluding patients with microinvasive/in situ disease. ${ }^{11,12}$

Similarly, only small retrospective series have demonstrated acceptable local control with RT alone in small, node-negative anal tumors. ${ }^{13,14,22-26}$ For example, Ortholan et $\mathrm{al}^{14}$ reported a series of 66 patients with Tis or T1 anal canal cancer treated with RT alone, resulting in local control rates of 91\%. Among 26 patients with T1 disease described by Deniaud-Alexandre et al, ${ }^{13} \mathrm{RT}$ alone resulted in local tumor control with sphincter conservation in $81 \%$. Although RT alone is arguably the most widely accepted treatment as a potential alternative to CRT, we observed that only $4.8 \%$ of patients in our cohort received RT alone.

In this national study of patients with stage I anal canal cancer treated from 2004 to 2012, only $61 \%$ of patients appeared to receive NCCN Guideline-concordant CRT therapy. One reason why such a large proportion of patients receive NCCN Guidelinediscordant care may be that less aggressive therapies are being delivered to patients with lower risk of disease recurrence. Indeed, the strongest predictors of NCCN Guideline-discordant care in our study were small tumor size and low grade, both of which have been associated with superior prognosis. ${ }^{19-21}$ However, factors independent of prognosis also appear to be involved in treatment selection. For example, men appear to be more likely to undergo excision alone despite the poorer prognosis observed with male sex. $\cdot^{19,27}$
Although we did not find an OS difference in patients receiving excision alone versus CRT, our data do not support changes to the management of stage I anal cancer. Importantly, local recurrence rates and salvage therapy use are not specified within the NCDB and remain unknown between these treatment groups. Especially in the setting of stage I anal canal cancer, for which survival is expected to be excellent, maintaining high rates of sphincter preservation and colostomy-free survival is a critical goal. Thus, before excision alone can be safely adopted into clinical practice, rates of local control and sphincter preservation should be prospectively tested and compared directly with CRT in a randomized trial or against historical controls.

Our study has several additional limitations. First, whether unmeasured factors may have affected treatment modality selection by the treating physician is unclear. For example, we lacked reliable data on several known prognostic factors for anal cancer, such as performance status and HPV status. ${ }^{28,29}$ Second, it is important to note that the NCDB is not a population-based dataset; thus, bias with regard to patient inclusion in the NCDB could have an impact on our observations of NCCN Guideline-discordant care rates. For example, it is possible that patients receiving excision alone could be overrepresented if they were more likely to receive care at an NCDBparticipating $\mathrm{CoC}$ member institution. Third, a small proportion of patients with missing data were excluded from Cox regression models. If these patients were more likely to receive a specific therapy, our exclusion may have introduced an unrecognized bias. Fourth, we were unable to control for underascertainment of data and errors in data reporting, which have been previously demonstrated in SEER registry data for breast and prostate cancers. ${ }^{30-32}$ If analogous underascertainment occurred within our NCDB dataset, the proportion of patients undergoing excision alone could be overestimated.

\section{Conclusions}

Significant treatment variability exists nationally among patients with stage I anal canal cancer based on age, sex, treatment facility type, and tumor size and grade. Although most patients 
Kole et al

$(\approx 60 \%)$ receive definitive CRT, as recommended by NCCN, a significant proportion of patients receive nonstandard therapies, most commonly excision alone. Modern prospective studies that define the optimal management of stage I anal canal cancer are urgently needed to assess whether commonly used treatments not supported by national guidelines are safe and effective. Importantly, data on local control, colostomy-free survival, and quality of life are essential for understanding whether patients can safely receive nonstandard care with acceptable outcomes.

\section{References}

1. Siegel RL, Miller KD, Jemal A. Cancer statistics, 2016. CA Cancer J Clin. 2016;66:7-30.

2. Benson AB III, Venook AP, Bekaii-Saab T, et al. NCCN Clinical Practice Guidelines in Oncology: Anal Carcinoma, Version 2.2016. Accessed February 8, 2017. To view the most recent version of these guidelines, visit NCCN.org.

3. Nigro ND, Vaitkevicius VK, Considine B Jr. Combined therapy for cancer of the anal canal: a preliminary report. Dis Colon Rectum 1974;17:354356.

4. Northover J, Glynne-Jones R, Sebag-Montefiore D, et al. Chemoradiation for the treatment of epidermoid anal cancer: 13-year follow-up of the first randomised UKCCCR Anal Cancer Trial (ACT I). Br J Cancer 2010;102:1123-1128.

5. Bartelink H, Roelofsen F, Eschwege F, et al. Concomitant radiotherapy and chemotherapy is superior to radiotherapy alone in the treatment of locally advanced anal cancer: results of a phase III randomized trial of the European Organization for Research and Treatment of Cancer Radiotherapy and Gastrointestinal Cooperative Groups. J Clin Oncol 1997;15:2040-2049.

6. Flam M, John M, Pajak TF, et al. Role of mitomycin in combination with fluorouracil and radiotherapy, and of salvage chemoradiation in the definitive nonsurgical treatment of epidermoid carcinoma of the anal canal: results of a phase III randomized intergroup study. J Clin Oncol 1996;14:2527-2539.

7. Gunderson LL, Winter KA, Ajani JA, et al. Long-term update of US GI intergroup RTOG 98-11 phase III trial for anal carcinoma: survival, relapse, and colostomy failure with concurrent chemoradiation involving fluorouracil/mitomycin versus fluorouracil/cisplatin. J Clin Oncol 2012;30:4344-4351.

8. James RD, Glynne-Jones R, Meadows HM, et al. Mitomycin or cisplatin chemoradiation with or without maintenance chemotherapy for treatment of squamous-cell carcinoma of the anus (ACT II): a randomised, phase 3, open-label, 2 × 2 factorial trial. Lancet Oncol 2013;14:516-524.

9. Kachnic LA, Winter K, Myerson RJ, et al. RTOG 0529: a phase 2 evaluation of dose-painted intensity modulated radiation therapy in combination with 5-fluorouracil and mitomycin- $\mathrm{C}$ for the reduction of acute morbidity in carcinoma of the anal canal. Int J Radiat Oncol Biol Phys 2013;86:27-33.

10. Boman BM, Moertel CG, O'Connell MJ, et al. Carcinoma of the anal canal. A clinical and pathologic study of 188 cases. Cancer 1984;54:114125.

11. Greenall MJ, Quan SH, DeCosse JJ. Epidermoid cancer of the anus. Br J Surg 1985;72(Suppl):S97-103.

12. Schraut WH, Wang CH, Dawson PJ, Block GE. Depth of invasion, location, and size of cancer of the anus dictate operative treatment. Cancer 1983;51:1291-1296.

13. Deniaud-Alexandre E, Touboul E, Tiret E, et al. Results of definitive irradiation in a series of 305 epidermoid carcinomas of the anal canal. Int J Radiat Oncol Biol Phys 2003;56:1259-1273.

14. Ortholan C, Ramaioli A, Peiffert D, et al. Anal canal carcinoma: earlystage tumors $<$ or $=10 \mathrm{~mm}$ (T1 or Tis): therapeutic options and original pattern of local failure after radiotherapy. Int J Radiat Oncol Biol Phys 2005;62:479-485.
15. Hu K, Minsky BD, Cohen AM, et al. 30 Gy may be an adequate dose in patients with anal cancer treated with excisional biopsy followed by combined-modality therapy. J Surg Oncol 1999;70:71-77.

16. Hatfield P, Cooper R, Sebag-Montefiore D. Involved-field, low-dose chemoradiotherapy for early-stage anal carcinoma. Int J Radiat Oncol Biol Phys 2008;70:419-424

17. Engstrom PF, Benson AB III, Saltz L, et al. Anal canal cancer. Clinical practice guidelines in oncology. J Natl Compr Canc Netw 2003;1:64-68.

18. Park HS, Gross CP, Makarov DV, Yu JB. Immortal time bias: a frequently unrecognized threat to validity in the evaluation of postoperative radiotherapy. Int J Radiat Oncol Biol Phys 2012;83:1365-1373.

19. Ajani JA, Winter KA, Gunderson LL, et al. Prognostic factors derived from a prospective database dictate clinical biology of anal cancer: the intergroup trial (RTOG 98-11). Cancer 2010;116:4007-4013.

20. Goldman S, Auer G, Erhardt K, Seligson U. Prognostic significance of clinical stage, histologic grade, and nuclear DNA content in squamous-cell carcinoma of the anus. Dis Colon Rectum 1987;30:444-448.

21. Clark MA, Hartley A, Geh JI. Cancer of the anal canal. Lancet Oncol 2004;5:149-157.

22. Allal A, Kurtz JM, Pipard G, et al. Chemoradiotherapy versus radiotherapy alone for anal cancer: a retrospective comparison. Int J Radiat Oncol Biol Phys 1993;27:59-66.

23. Cummings BJ, Keane TJ, O'Sullivan B, et al. Epidermoid anal cancer: treatment by radiation alone or by radiation and 5 -fluorouracil with and without mitomycin C. Int J Radiat Oncol Biol Phys 1991;21:1115-1125.

24. Eschwege F, Lasser P, Chavy A, et al. Squamous cell carcinoma of the anal canal: treatment by external beam irradiation. Radiother Oncol 1985;3:145-150.

25. Martenson JA Jr, Gunderson LL. External radiation therapy without chemotherapy in the management of anal cancer. Cancer 1993;71:17361740 .

26. Schlienger M, Krzisch C, Pene F, et al. Epidermoid carcinoma of the anal canal treatment results and prognostic variables in a series of 242 cases. Int J Radiat Oncol Biol Phys 1989;17:1141-1151.

27. Glynne-Jones R, Sebag-Montefiore D, Adams R, et al. Prognostic factors for recurrence and survival in anal cancer: generating hypotheses from the mature outcomes of the first United Kingdom Coordinating Committee on Cancer Research Anal Cancer Trial (ACT I). Cancer 2013;119:748-755.

28. Serup-Hansen E, Linnemann D, Skovrider-Ruminski W, et al. Human papillomavirus genotyping and p16 expression as prognostic factor for patients with American Joint Committee on Cancer stages I to III carcinoma of the anal canal. J Clin Oncol 2014;32:1812-1817.

29. Martenson JA, Lipsitz SR, Lefkopoulou M, et al. Results of combined modality therapy for patients with anal cancer (E7283). An Eastern Cooperative Oncology Group study. Cancer 1995;76:1731-1736.

30. Jagsi R, Abrahamse P, Hawley ST, et al. Underascertainment of radiotherapy receipt in Surveillance, Epidemiology, and End Results registry data. Cancer 2012;118:333-341.

31. Walker GV, Giordano SH, Williams M, et al. Muddy water? Variation in reporting receipt of breast cancer radiation therapy by population-based tumor registries. Int J Radiat Oncol Biol Phys 2013;86:686-693.

32. Wang K, Sheets NC, Basak R, Chen RC. Ascertainment of postprostatectomy radiotherapy for prostate cancer in the Surveillance, Epidemiology, and End Results database. Cancer 2016;122:3069-3074. 